\title{
Features of choosing the schemes for selective mining of ores and justifying their rational parameters while using heap leaching schemes for processing
}

\author{
Gennady Sekisov ${ }^{1,2 *}$, Aleksei Sobolev ${ }^{1}$ and Abdakim Ashimbaev ${ }^{3}$ \\ ${ }^{1}$ Mining Institute FEB RAS, 51 Turgenev st., Khabarovsk, 680000, Russia; \\ ${ }^{2}$ Transbaikal State University, 672039, Russia, Chita, Aleksandro-Zavodskaya street 30; \\ ${ }^{3}$ Kyrgyz State University named after I. Razzakov, 720044, Kyrgyzstan, Bishkek, prospect Mira, 66
}

\begin{abstract}
The article presents data from theoretical and experimental studies related to the search for a solution to an urgent geotechnological problem - selective mining of standard quality ore, substandard and diluted ores, taking into account the peculiarities of their processing by heap leaching. For complex-structural large-scale ore deposits of the stockwork morphological-structural type, multilevel heterogeneity is typical. The morphology and structure of the objects of direct extraction ore bodies within the production blocks - vary significantly. The expediency of selective mining and separate heap leaching (or heap oxidation and leaching) of gold and copper from conditioned ores of various geological and technological types and grades is justified. In addition, it is advisable to selectively extract and separately process by heap leaching or flux in a controlled manner before it off-balance and diluted ores, as well as mineralized overburden and tailings of high-grade ores.

Keywords: selective mining, cut-off grade ore, diluted ore, heap leaching parameters and modes, heap oxidation, activated solutions, staged heap leaching, fine gold, copper leaching, oxidative preparation.
\end{abstract}

\section{Introduction}

At present, a relatively technologically simple method of ore processing is becoming more widespread - heap leaching (HL), which makes it possible to involve off-balance and diluted ores into processing, as well as mineralized overburden rocks, which are inevitably extracted from the depths during open-pit mining. Globally, the share of gold and copper produced using heap leaching already exceeds $40 \%$. The need for further growth in the scale of its use is associated not only with the persistence of a tendency towards a decrease in the quality of ores of the mined deposits, but also with the progressive growth of mining waste containing both valuable components and pollutants for the environment. The significant duration of the development of large deposits implies a change in time in the

${ }^{*}$ Corresponding author: sekisovag@mail.ru 
industrial value of the elements contained in the waste produced in this case, since with a long time the disintegrated mineral mass remains on the surface of the earth, due to the manifestation of a complex of natural and climatic factors, the migration of the main and accompanying ore-forming elements occurs, which in addition to those losses causes environmental pollution.

Despite a number of indisputable technological and economic advantages of heap leaching, its main disadvantage is the low recovery of valuable components, which limits its use in the processing of mineral raw materials with low contents of valuable components. The use of fine crushing and pelletizing does not always overcome this disadvantage. Further prospects for the development of heap leaching of gold and copper are associated with solving the problems of developing effective processes for preliminary heap oxidation of refractory ores, increasing the degree of recovery of dispersed forms of finding noble metals by ensuring the necessary permeability for leaching solutions of ore units, using innovative processes of converting them into productive solutions. The solution of these problems will make it possible to make the heap leaching method comparable in profitability to the traditional schemes of extraction and processing of conditioned ores. This will significantly increase the utilization of reserves and reduce environmental costs.

\section{Theoretical and experimental foundations of selective heap leaching}

The first stage in increasing the efficiency of the HL, which can be implemented already at the present time, is the use of differentiated processing of ores and diluted ore mass, selectively extracted during mining, provision of differentiated preparation of the mineral mass, its stacking and effective filtration of working solutions through it.

Taking into account the features of the deposits considered above, namely the high variability of the parameters of standard quality ores and substandard ores of non-ferrous and precious metals, as well as the fact that the dilution of ores occurs as a result of mixing rocks of various material composition with them, it is advisable to distinguish the following objects of selective mining for heap leaching.

Ores with different types of mineralization are distinguished according to technological types: vein, veinlet, vein-disseminated, disseminated (with subtypes with different density and size of dissemination of ore and vein minerals).

By ore grades with a content of valuable components (reduced by value to the main one), providing a profit (NPV), comparable to the profit obtained when processing ores according to the traditional beneficiation-hydrometallurgical processing, ore with a content below the standard for the traditional beneficiation-hydrometallurgical processing, but approaching it with an increase in the price of the main recoverable component, ore (mineral mass) with a grade ranging from a level that provides payback for the cost of obtaining the final product according to the heap leaching scheme to the level of grade in the tailings.

Diluted ore, in addition to the main features of separation into types and grades, is proposed to divide into ore with rock mixed during excavation, inert from the standpoint of its interaction with leaching and productive solutions (does not produce material that cause clogging, does not sorb dissolved valuable components, does not interact with oxidants and complexing agents of technological solutions) and ore with technologically active enclosing rock mixed during excavation (with division into subspecies).

When mining complex-structured deposits of non-ferrous and noble metals, as a rule, there is a problem of oxidation of gold-bearing sulfide, sulfoarsenide minerals, as well as carbonaceous matter, which causes parasitic sorption of dissolved gold (preg-robbing 
effect), and iron-containing sulfides (pyrite, pyrrhotite), which cause unproductive consumption of reagents. When using the heap leaching technology on ores containing harmful impurities (sulfides, carbonaceous-bearing rocks, etc.), preliminary use of special working solutions with oxidizers, or with certain types of bacteria oxidizing iron and sulfur, is required, which complicates and increases the cost of ore processing.

Numerous studies on the dissolution of gold carried out in the Russian Federation and abroad [1-24] show that during the processing of refractory ores, chlorine is the most suitable solvent for industrial use, alternative to cyanides of alkali and alkaline earth metals. Chlorine, like other halogens, is a complexing agent for native gold and, at the same time, an oxidizing agent for most sulphide minerals and carbonaceous matter. In aqueous solutions, chlorine is in ionic form and in compounds with oxygen (the so-called active chlorine). Active chlorine interacts intensively with iron and a number of other mineralforming metals, sulphur, metalloids. Accordingly, at the first stage of interaction with ore containing sulphide minerals in significant quantities, it does not participate in complexation reactions with gold, but allows the extraction of such valuable components as copper and silver (the latter in colloidal form or colloidal-ionic form). The problem of unproductive consumption of chlorine and (or) its compounds, for the processing conditions of such ores, can also be solved by preliminary chemical (primarily sulfuricperoxide) and/or bacterial oxidation of sulphide minerals.

In addition to the problems of effective oxidation of refractory varieties of selectively extracted ores and mineral mass as a whole, the problem of choosing for each of them the required degree of crushing, on the one hand, provides access to solutions to ore mineral grains, on the other hand, excludes clogging of the stack, rational modes and parameters of irrigation with technological solutions.

The density of ore irrigation, as well as the filtration coefficient (filtration rate) in the case of HL, are integral indicators, since their values are established empirically based on the general analysis of the kinetics and dynamics of gold leaching, with a fixed value of other parameters: ore crushing size, cyanide concentration, specific volume of the pore space of the ore, its moisture content, etc.

At the same time, in fact, the kinetics and dynamics of leaching depend on more "fine" physicochemical parameters; the rate of penetration of the solution into microcracks and pores of minerals, the rate of diffusion of molecules (ions) of reagents to the surface of microcracks and pores, their consumption for interaction with absorbent elements (in the case of using cyanide-cyanosides), sorption by clay-mica minerals and carbonaceous inclusions. Therefore, no less important technological parameters for HL processes are the reagent concentration in the working (leaching) solution and the dynamics of its change.

Based on a large amount of experiments on the activation HL of gold from ores of deposits of various formational types (Muruntau, Kokpatas, Darasun, Baley, Pogromnoye, etc.), it can be concluded that the diffusion stage of leaching is determinative. Therefore, it is advisable to add cyanide in the form of a concentrated solution or powder during pelletizing (in terms of the concentration in dissolved form when it interacts with water added to the process).

In the absence of the possibility to use pelletizing, at the first stage of HL, it is advisable to carry out irrigation with concentrated solutions with a reduced specific consumption (respectively, by the irrigation density), which ensures the formation of wetting films on the surface of ore units and capillary-diffusion penetration into pores and microcracks of leaching solutions and/or their components.

In this case, at the first stage, there may be a relative slowdown in the release of goldcyanic complexes into the main volume of the formed productive solution (with their accumulation in the pore space and in the film liquid), due to the low intensity of their convective mass transfer processes with the filtering flow of the working solution. But at 
the second stage, with an increase in irrigation intensity, the accumulated gold complexes, due to the high concentration gradient and filtration coefficient, pass into the productive solution and, as a result, the total gold recovery will be higher than in the case of uniform irrigation with a high specific density. Moreover, due to the components of the active solution, additional dispersed gold will be extracted.

The pelletizing of finely crushed ores using a small (less than the moisture saturation limit) volume of the active solution and keeping the pelletized mass in a stack provides a relatively intensive course of the processes discussed above. To reduce the effect of further "idle" migration of gold with microcracked waters when moving them through closed capillary systems, after feeding of leaching solutions into the pelletized mass, the intensity of their irrigation of the pelletized mass at the stage of infiltration or filtration leaching should be optimized. In the case of an infiltration hydrodynamic leaching regime, the solution should be fed 0.5-2 days after placing the mineral mass in a percolator with a specific irrigation density of a working solution of $5-71 / \mathrm{m}^{2 *}$ hour. With a longer holding time of the mineral mass (3-5 days) required for the full implementation of diffusion and mass transfer processes in the mineral mass, with a dense structure and a weakly oxidized material base, it is advisable to use a filtration hydrodynamic leaching regime. Therefore, the specific density of irrigation with a solution, at least on the first day after the pelleted mass has stood, should be at least $101 / \mathrm{m}^{2 *}$ hour. In both cases, the specific consumption of the solution does not usually exceed $0.75 \mathrm{~m}^{3} / \mathrm{t}$ of ore, and the consumption of sodium cyanide is $1.5 \mathrm{~g} / \mathrm{t}$.

For mining enterprises, the main product or by-product is gold, despite the projected rise in prices for it, capital and operating costs are an invariably important characteristic of the production of final products, which, in turn, depend on the resources consumed: initial mineral raw materials and production - labor, energy, material and technical. Losses in the abandoned pillars, in special dumps of off-balance ores, due to a number of reasons, are most often completely or partially transformed into irrecoverable losses. Gold losses in sorting and beneficiation tailings, cyanidation cakes, waste heap leaching piles and sludge ponds, in total, can reach $50 \%$ or more of the original amount of gold in the balance reserves. For complex-structural ore deposits of the stockwork morphological-structural type, characterized by a multilevel heterogeneity of distribution and the ratio of forms of gold occurrence, virtual losses are also significant (primarily, ore bodies or conditioned areas within off-balance ores that were not identified during detailed and operational exploration).

Selective excavation for the separate formation of stacks, the formation of stacks with layer-by-layer stacking of ores or controlled blending of ores is proposed to be carried out in the following sequence. When drilling the current mined block, samples of drill cuttings are taken, according to the data of analysis and express technological testing for leachability and sludgeability of which, as well as according to the data of testing the wells of the previously worked out layer of the overlying horizon, the objects of selective extraction are distinguished. The central ("nuclear") parts of small ore bodies are distinguished and the zone of mixing (with ore of a different type/grade or host rocks during extraction). Blasting is carried out with maximum preservation of the geological structure and subsequent excavation with a hydraulic excavator or front loader.

The choice of schemes for blasting preparation, selective mining, ore sorting and/or averaging should be carried out in conjunction with the choice of rational options for the development of mining operations, taking into account the technological features of processing the resulting ore mass by traditional methods and heap leaching by types and grades, forming from substandard rock mass and the resulting tailings beneficiation of stacks and subsequent extraction of useful components from them using heap leaching [2]. 
In the last 5-10 years, even in such software systems as "Data mine", the selection of the optimal parameters for the development of open pit mining uses complex economic indicators, in particular, the net present value (NPV). Despite the full accounting and quantitative assessment of all factors that determine the feasibility of the compared options, such complex indicators do not correspond to the level of reliability of the initial geological information in the development of complex-structured deposits. In this regard, as it was argued in due time in the works of A.I. Arsentyev, V.G. Bliznyukov, S.V. Kornilkov, G.G. Lomonosov, V.I. Papicheva, S. S. Reznichenko, V. A. Khakulova, V.S. Khokhryakova, B.P. Yumatov and other researchers, to select an effective option for the development of open pit mining, it is more expedient to use technological indicators such as the current coefficient of rock mass $\left(\mathrm{K}_{\text {r.m. }}\right)$ or similar specific parameters.

To select the order of development and technological schemes for conducting open pit mining, in a single complex with the choice of parameters for the formation of piles of HL and special dumps, technologies and time for the subsequent processing of technogenically transformed mineral raw materials, we propose to use as a criterion the maximum natural indicator - the amount of recovered metal $\left(\mathrm{M}_{\text {пр }}\right)$, with a set of economic parameters:

$$
\begin{gathered}
\mathrm{M}_{\text {пр }}=\sum_{i=1}^{N} \sum_{j=1}^{M} h \cdot S \cdot \bar{c}_{i j}\left[\mathrm{~K}_{\mathrm{p}} \mathrm{K}_{\mathrm{H}} \mathrm{K}_{\mathrm{o}} \cdot \frac{Ц_{\mathrm{tj}}}{3 \cdot\left(1+\mathrm{q}_{\mathrm{S}} \cdot \mathrm{n} \cdot \mathrm{Z}_{\mathrm{q}}\right)}+\left(1-\mathrm{K}_{\mathrm{H}} \mathrm{K}_{\mathrm{p}}\right) \mathrm{K}_{\mathrm{M \Pi t}} \cdot \mathrm{T} \cdot \mathrm{K}_{\Pi} \cdot \frac{Ц_{\mathrm{tj}}}{3^{\prime}}+\right. \\
\left.+\left(1-\mathrm{K}_{\mathrm{p}} \cdot \mathrm{K}_{\mathrm{н}} \cdot \mathrm{K}_{\mathrm{o}}\right) \cdot \mathrm{K}_{\text {мпt }}^{\prime} \cdot \mathrm{T} \cdot K_{\Pi} \cdot \frac{Ц_{\mathrm{tj}}}{3^{\prime \prime}}\right] \rightarrow \max ,
\end{gathered}
$$

where $\mathrm{i}, \mathrm{j}$ - respectively, the index of the ore block and the type of valuable component extracted from ores

$\mathrm{N}$ and $\mathrm{M}$ - respectively, the number of indexed ore blocks and types of the valuable component

$\mathrm{h}, \mathrm{S}$ - respectively, the height of the bench, $\mathrm{m}$ and the area of the ore block, $\mathrm{m}^{2}$

$C_{\text {ij }}$ - content of the j-th component in the i-th block ( $\%$ or $\mathrm{g} / \mathrm{t}$ )

$K_{\mathrm{p}}, K_{\mathrm{H}}, \mathrm{K}_{\mathrm{o}}$ - respectively, the coefficients of ore content, extraction from the subsoil and extraction during beneficiation, unit fraction.

$\bigsqcup_{\mathrm{t} j}$ - selling price (forecasted) of the $\mathrm{j}$-th component in the $\mathrm{t}$-th year, rubles.

$3,3^{\prime}, 3^{\prime \prime}$ - costs of obtaining the final product when extracting, respectively, from the balance, off-balance ore (special dumps), primary processing tailings, rub.

$K_{\text {мпा }}, K_{\text {мпा }}^{\prime}$-coefficients of migration losses from dumps and tailings in $t$-th year, unit fraction.

$\mathrm{T}$ - evaluation period, years

$\mathrm{K}_{\Pi}, \mathrm{K}_{\Pi}^{\prime}$ - respectively, metal recovery coefficients during secondary processing by traditional methods or by heap leaching from ores, diluted ore mass, special dumps or tailing dumps, unit fracture.

$\mathrm{q}_{\mathrm{s}}$ - the gradient of the overburden area growth with increasing pit depth for a particular block, unit fracture

$\mathrm{n}$ - number of overburden benches above the i-th ore block

$\mathrm{Z}_{\mathrm{q}}$ - share of costs for ore mining in the total cost structure for obtaining the final product, unit fraction

\section{Results and discussion}

Based on the experimental studies obtained, which made it possible to prove the effectiveness of the selective mining of ores, taking into account the peculiarities of their 
processing according to the heap leaching scheme, a methodological basis for the selection of technological type-grades of ores was developed, technological schemes for the formation of piles for HL were developed, the parameters and modes of heap oxidationleaching of valuable components from substandard oxidized porphyry gold-copper ores were substantiated. With the direct participation of the authors, a system of selective mining - heap leaching has been developed, including the delineation of mining elements with different gold and copper contents within the blocks of off-balance ores, as well as residual sulfide sulfur, which is transformed into sulfate during oxidative treatment. The ore in the volume of the entire block is considered off-balance in terms of both copper and gold grades $\left(\mathrm{C}_{\mathrm{Au}}<\mathrm{C}_{\mathrm{Au} \text { min }}\right.$ and $\mathrm{C}_{\mathrm{Cu}}<\mathrm{C}_{\mathrm{Cu} \text { min }}$ - gold and copper grades are below the minimum commercial grade), but mining elements with increased gold and sulfur content can be distinguished inside the block. Selectively extracted ore inclusions with different quality parameters in this case are stacked in common piles. A feature of the proposed stack design is its layer-by-layer structure (fig. 1). In the lower layer 3 of the stack 1, ore of a lowsulphide technological type is placed, and in the intermediate layer 4, ore of the sulphide type is laid.

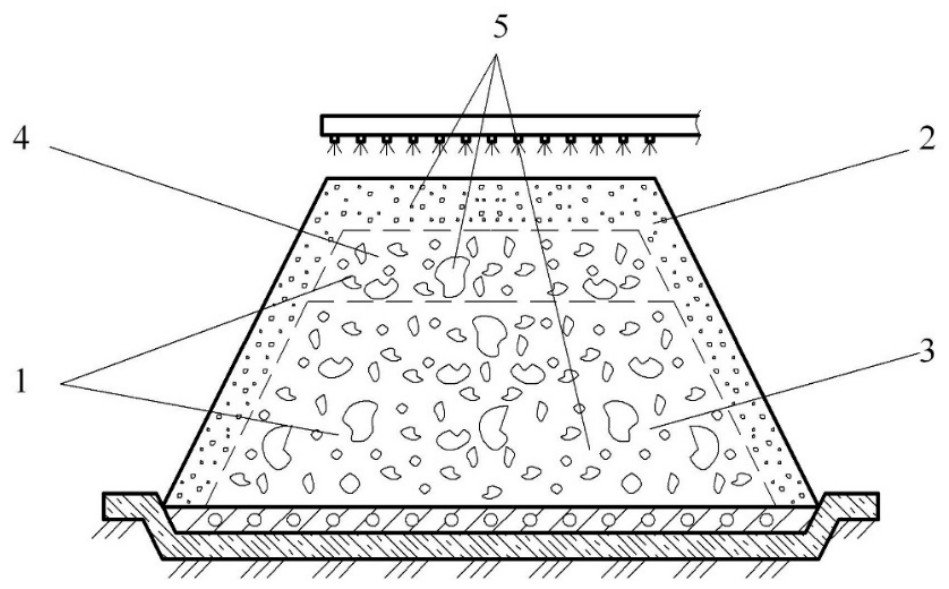

Fig. 1. Scheme of heap leaching from porphyry copper-gold ores:

1 - a pile of oxidized ore; 2 - additional layer; 3 - bottom layer; 4 - intermediate layer; 5 - stack

The main layer of ore 2 is represented by its technological grade, distinguished on the basis of an increased gold content $\left(\mathrm{C}_{\mathrm{Au}} \geq \mathrm{C}_{\mathrm{Au}}\right.$ min - the gold content is higher than the minimum payback when using the heap leaching method, while $\mathrm{C}_{\mathrm{Cu}}<\mathrm{C}_{\mathrm{Cu} \text { min }}$ - the copper content is below the minimum for the use of this technology) ore. Together, these layers form a stack 5. After the formation of the stack, a differentiated extraction of useful components with solutions of different composition is carried out.

The additional layer 2 and the intermediate layer 4 are initially irrigated with a sulfuric acid solution that has undergone electrophotochemical treatment with the formation of peroxide complexes in it. Additional layer 2 is impregnated to full moisture saturation with an active hypochlorite-chloride solution. To ensure the leaching of gold from this layer in the penetration-diffusion hydrodynamic mode, a technological pause is maintained. The preparation of heap 1 with the bulk of the ore of copper grade for subsequent leaching due to the oxidation of sulfide minerals and general destruction is in progress. After maintaining a pause, intensive irrigation of the entire material of the stack 5 with a low-concentration hypochlorite-chloride solution or water is carried out to ensure the filtration hydrodynamic regime of gold leaching. After the completion of gold leaching, a second technological pause is maintained for the natural processes of oxidation of the entire material of the stack 
5 with atmospheric oxygen and the formation of additional sulfuric acid during the reaction of residual reagents with the mineral mass of the intermediate layer 4 with an increased content of sulfide sulfur.

Thus, as a result of the studies carried out, the viability of selective mining of ores processed by the heap leaching method and the possibility of implementing the corresponding technological schemes already at present have been substantiated.

\section{References}

1. B.P. Yumatov, G.V. Sekisov, M.I. Buyanov, Rationing and planning of the completeness and quality of ore extraction in open pits (Moscow: Nedra, 1987)

2. B.P. Yumatov, Z.I. Valatka, A.G. Sekisov, N.V. Zykov, Gornyi Zhurnal, 12 (1984)

3. V.V. Ivanov, V.V. Kononov, E.K. Ignatiev, Tectonics, deep structure and minerageny of East Asia: VIIIth Kosygin readings: materials of all-Russian conference, September 17-20, 2013, Khabarovsk, 258-261 (Vladivostok: Dalnauka, 2013)

4. A.G. Sekisov, A. Yu. Lavrov, A.V. Rasskazova, Photochemical and electrochemical processes in geotechnology (Chita, 2019)

5. V.S. Litvintsev, T.S. Banshchikova, N.A. Leonenko, V.S. Alekseev, Journal of Mining Science, 48(1), 198-202 (2012)

6. S. Yin, L. Wang, A. Wu, M.L. Free, E. Kabwe, Journal of cleaner production, 202, 321-331 (2018)

7. A.G. Sekisov, A. Yu. Lavrov, D.V. Manzyrev, Bulletin of ChitSU, 69, 106-111 (2011)

8. E.A. Holley, Y.T. Yu, A. Navarre-Sitchler, Hydrometallurgy, 181, 130-142 (2018)

9. P.J. Van Staden, J. Petersen, Minerals engineering, 128, 202-214 (2018)

10. L. Velasquez-Yevenes, D. Torres, N. Toro, Hydrometallurgy, 181, 215-220 (2018)

11. I. Yu. Rasskazov, M. A. Gurman, T. N. Aleksandrova, Tikhookeanskaya geologiya, 33(4), 75-83 (2014)

12. G. R. O'neil, Recovery of gold from carbonaceous ores by simultaneous chlorine leach and ion exchange resin adsorption process : Pat. 4723998 USA (1988)

13. M. G. Hasab, F. Rashchi, S. Raygan, Minerals Engineering, 50, 140-142 (2013)

14. I. De Michelis et al., International Journal of Mining Science and Technology, 23(5), 709-715 (2013)

15. L. S. Pangum, R. E. Browner, Minerals Engineering, 9(5), 547-556 (1996)

16. M. G. Hasab, F. Rashchi, S. Raygan, Hydrometallurgy, 142, 56-59 (2014)

17. K. S. Pak. et al., Hydrometallurgy, 105325 (2020)

18. Q. Wang et al., Minerals Engineering, 136, 89-98 (2019)

19. H. Li et al., Separation Science and Technology, 1-9 (2019)

20. S. Harjanto et al., IOP Conference Series: Materials Science and Engineering. IOP Publishing, 2019, 515(1), 012032 (2019) 